\title{
PERANAN PEN YULUH DALAM PEMBINAAN KELOMPOK USAHA BERSAMA PETERNAKAN BABI "SINGKATUHANG" (Studi Kasus Di Kelurahan Buha Kecamatan Mapanget)
}

\author{
Rizky A. Karungu, B. F. J. Sondakh*, F. S. Oley, A. A. Sajow
}

Fakultas Peternakan Universitas Sam Ratulangi Manado, 95115

\begin{abstract}
ABSTRAK
Penelitian ini telah dilakukan pada bulan April - Agustus 2019 di Kelurahan Buha Kecamatan Mapanget Kota Manado, yang bertujuan untuk mengetahui peranan penyuluh (peternakan) dalam membina dan merubah prilaku (pengetahuan, ketrampilan dan sikap) peternak pada kelompok usaha bersama ternak babi "Singkatuhang" (bahasa Bantik artinya persaudaraan), tentang cara mengelola sistem berternak babi yang tepat. Penelitian ini adalah kualitatif dimana data yang diperoleh dengan menggunakan metode observasi dan wawancara setelah diolah kemudian dijelaskan secaradeskriptif. Data primer meliputi semua aktifitas kelompok dan usaha peternakan babi diambil dari ketua/anggo ta kelompok "Singkatuhang" dan kepala bidang penyuluhan/penyuluh lapangan, sedangkan data sekunder meliputi keadaan umum wilayah dan institusi penyuluhan yang diambil dari kantor kelurahan dan Dinas Pertanian, Kelautan dan Perikanan Kota Manado. Skala ordinal digunakan untuk mengukur prilaku dan skala rasio digunakan untuk mengukur keuntungan kelompok.Berdasarkan hasil analisis dapat disimpulkan bahwa Peranan penyuluh telah merubah prilaku (pengetahuan, sikap dan ketrampilan) peternak dan mempengaruhi (cukup meningkatkan) pendapatan peternak kelompok usaha bersama ternak babi "Singkatuhang", dibandingkan dengan upah minimum Provinsi Sulut 2019.
\end{abstract}

Kata kunci :Peranan Penyuluh, Pembinaan Kelompok

*Korespondensi (corresponding author):

Email: bfjsondakh@yahoo.com

ABSTRACT

THE ROLE OF EXTENSION WORKER
IN FOSTERING A JOINT VENTURE
PIGBUSINESS
"SINGKATUHANG"(A Case Study in Buha village, Mapanget SubDistrict). The research had been done from April until August 2019, in Buha village, Mapanget district, Manado city. The aim of this research was to find out the role of extension workers (animal husbandry instructor) in fostering and changing the behavior (knowledge, skill and attitude) of farmers in a joint venture pig business groups "Singkatuhang" (Bantik ethnic language means brotherhood) on how to manage the proper pig raising system. This research was a qualitative research, where the data were obtained using observation and interview methods, after data processing then descriptively explained. Primary data covering all group activities and pig breeding business were taken from "Singkatuhang" group leader or members and the head of field extension workers, while secondary data covering the general condition of the region and extension institutions were obtained from Buha village office and Manado city of Agricultures, Marines and Fisheries office. An ordinal scale was used to measure behavior variables and Ratio scale was used to measure group profits. Based on the analysis results, it can be concluded that the role of extension workers has been changed the farmers' behavior and influenced (quietly increased) the farmers' income in a joint venture pig business group "Singkatuhang" compared to the minimum wage in North Sulawesi province 2019.

Keywords : Extension Workers, Group Coaching. 


\section{PENDAHULUAN}

Dalam artian etimologis, pengertian penyuluhan adalah usaha memberikan keterangan, penjelasan, petunjuk, bimbingan, tuntunan, jalan dan arah yang harus ditempuh oleh setiap orang sehingga dapat memecahkan masalah yang dihadapinya dan meningkatkan kualitas hidupnya.Mengingat pentingnya peranan penyuluh kepada petani penyuluh diminta mempunyai kompetensi dan kinerja yang tinggi (Hidayat, 2009).

Nlerum et al. (2015) yang menunjukan bahwa metode penyuluhan yang baik digunakan adalah metode demonstrasi kelompok.Permasalahan di lapangan yang berkaitan dengan penyuluhan ialah masih kurangnya prilaku yang baik(pengetahuan, ketrampilan dan sikap) dalam berternak, berdasarkan hasil penelitian Ali-Olubandwa et al. (2011) metode penyuluhan kelompok merupakan yang paling efektif dengan biaya murah sehingga menyarankan agar menggunakan metode penyuluhan kelompok. Dengan adanya kegiatan penyuluhan diharapkan dapat memberikan dampak positif dalam hal ini terjadinya perubahan perilaku terhadap peternak babi.

Program peternak babi Singkatuhang Buha adalah meningkatkan pendapatan anggota melalui usaha ternak babi, pelaksanaan program ini membutuhkan peternak dalam berbagai kegiatan yang diadakan, karena pada dasarnya peternaklah yang melaksanakan kegiatan-kegiatan tersebut. Kegiatan tersebut meliputi penyusunan rencana, pelaksanaan kegiatan dan pasca panen, kenyataan yang berlaku di kelompok Singkatuhang Buha bahwa partisipasi peternak daya saing, pengetahuan tentang pemeliharaan untuk pengembangan usaha ternak babi masih rendah, penyuluh yang produktif dapat mengikuti perkembangan teknologi - teknologi baru

(Ali et al., Bahua et al., 2013).

Menurut Harinta (2011) untuk tercapainya perubahan - perubahan perilaku peternak demi terwujudnya perbaikan mutu hidup perlu disampaikan melalui kegiatan penyuluhan dan inovasi tidak hanya sekedar sesuatu yang baru sehingga dapat mendorong terjadinya pembaharuan dalam masyarakat. Kontribusi teknologi, dukungan kelembagaan dan peran penyuluhan memiliki pengaruh nyata terhadap tingkat adopsi oleh peternakPriyono et al. (2015).Berdasarkan hasil penelitian Sapar et al. (2012) penyuluh yang berhasil adalah penyuluh yang dapat merancang dan melaksanakan suatu program pembelajaran, dimana materi dan metodenya sesuai dengan kondisi dan karakteristik petani, pernyataan ini juga di tunjang oleh Anwas (2013) dalam penelitiannya menggungkapkan bahwa intensitas pelatihan memberikan efek signifikan terhadap pemberdayaan petani. 


\section{METODE PENELITIAN}

\section{Waktu dan Tempat Penelitian}

Penelitian ini telah dilakukan pada bulan April - Agustus 2019, pada kelompok usaha bersama ternak babi "Singkatuhang", di Kelurahan Buha Kecamatan Mapanget Kota Manado.

\section{Jenis Penelitian}

Metode yang digunakan merupakan penelitiandeskriptif kualitatif yaitu yang bersifat menjelaskan bagaimana peranan penyuluh dalam pembinaan kelompok usaha bersama ternak babi "Singkatuhang", lebih jauh menurut pendapat Moleong (2007) menjelaskan penelitian kualitatif adalah penelitian bermaksud memahami fenomena tentang apa yang dialami oleh subjek penelitian, dengan cara deskripsi dalam bentuk kata-kata dan bahasa pada suatu konteks khusus berasal dari wawancara, pengamatan, termasuk kutipan-kutipan dan rangkuman dari dokumen.

Jenis penelitian kualitatif yang digunakan adalah studi kasus pada kelompok usaha bersama ternak babi "Singkatuhang", Susilo at al.(2011)menyatakan bahwa studi kasus merupakan metode yang di terapkan untuk memahami individu lebih mendalam dengan dipraktekan secara integratif dan komprehensif.

\section{Sumber Data}

Data primer : Meliputi semuaaktifitas kelompok dan usaha peternakan babi diambil dari ketua/anggota kelompok"Singkatuhang” dan kepala bidang penyuluhan/penyuluh lapangan.

Data sekunder : Meliputi keadaan umum wilayah dan institusi penyuluhan diambil dari kantor kelurahan dan dan kantor dinas terkait kota Manado.

\section{Teknik Pengumpulan Data}

Pengumpulan data penelitian ini menggunakan metode observasi dan wawancara/interview menggunakan kuesioner/daftar pertanyaan.Daftar pertanyaan tersebut berkaitan dengan permasalahan penelitian yang harus dijawab oleh responden, dalam hal ini pengurus dan anggota KUB ternak babi "Singkatuhang" dan kepala bidang penyuluhan dan penyuluh lapangan dari Dinas Pertanian, Kelautan dan Perikanan Kota Manado.

\section{Analisis Data}

1. Analisis metode kualitatif (secara deskriptif dan tabulasi) terhadap variable peranan penyuluh dan pengaruhnya terhadap kelompok dan dikaitkan dengan teori-teori yang ada.

2. Analisis metode kuantitatifsebagai data penunjang terhadap keuntungan kelompok usaha bersama peternakan babi "Singkatuhang" menggunakan rumus :

TR = Hasil Penjualan Ternak (Total Revenue)

$\mathrm{TC}=$ Fix Cost + Variable Cost

Total Revenue (TR) - Total Cost $(\mathrm{TC})=$ Pendapatan (keuntungan) 


\section{Definisi Variable dan Pengukuran}

Variabel dalam penelitian ini yaitu:

1. Peranan penyuluh, peran merupakan aspek dinamis kedudukan (status), apabila seseorang melaksanankan hak dan kewajiban sesuai dengan kedudukannya, maka ia menjalankan suatu peranan (Soekanto, 2002) (Skor)

2. Pembinaan kelompok, adalah usaha untuk meningkatkan kinerja, tindakan dan kegiatan yang dilakukan untuk memperoleh hasil yang lebih baik (Ivancevich, 2008). (Skor)

3. Keuntungan, adalah peningkatan kekayaan seorang investor dari hasil penanaman modalnya, setelah dikurangi biaya - biaya yang berhubungan dengan penanaman modal tersebut. (Rp/periode)

4. Pengetahuan, yaitu perubahan tingkat informasi yang menyangkut perubahandari apa yang diketahui yang sifatnya kurang menguntungkan menjadi lebih baik dan menguntungkan diukur dengan persentasi peternak yang terampil terhadap indikator pengetahuan peternak $(\%)$

5. Ketrampilan, yaitu seseorang yang mampu memelihara ternak babi yang mampu menangani setiap masalah dalam beternak diukur dengan persentasi peternak yang semakin terampil memelihara ternak sapi $(\%)$

6. Sikap, yaitu reaksi atau respon seseorang yang mampu menerima dan memahami setiap ide-ide dan inovasi yang diberikan oleh penyuluh untuk diterapkan oleh peternak dan menjalankannya dengan baik diukur dari persentasi peternak yang bersikap baik terhadap indikator sikap dalam memelihara ternak babi (\%)

Variabel yang diukur dalam penelitian ini adalah peranan penyuluh dan pembinaan kelompok, peranan penyuluh merupakan suatu ukuran tingkat pencapaian hasil pelaksanaan kegiatan penyuluhan untuk keberhasilan perkembangan kelompok.Sedangkan pembinaan kelompok adalah usaha untuk mengembangkan kemampuan sesuai dengan perannya dalam kelompok tersebut.Dalam hal ini adalah perubahan perilaku peternak (pengetahuan, ketrampilan dan sikap) dan keuntungan kelompok sebagai data penunjang.Indikator variabel dijabarkan menjadi parameter, parameter tersebut dijadikan sebagai titik tolak untuk menyusun item - item instrument yang berupa pernyataan dan pertanyaan.

Alat analisis yang digunakan dalam pengukuran parameter penelitian dilakukan dengan menerapkan skala 
ordinal dan rasio untuk mengetahui keuntungan kelompok yang pengukurannya diberi skor untuk setiap parameter. Dalam membantu analisis data digunakan skor persentase untuk pertanyaan dengan respon yang termasuk dalam kategori tahu/tidak tahu, terampil/tidak terampil dan baik/tidak baik diberikan skor persentase sesuai respon dari anggota kelompok "Singkatuhang", penerapan skala rasio diberikan skor harga (rupiah) untuk dijumlahkan agar dapat diketahui apakah kelompok tersebut profitable(untung).

\section{HASIL DAN PEMBAHASAN}

\section{Keadaan Umum Kelurahan Buha}

Kelurahan Buha merupakan salah satu bagian dalam wilayah adat masyarakat suku Bantik yang ada di Manado, secara keseluruhan di Kota Manado terdapat 6 Kelurahan lainnya yang masih termasuk wilayah Adat Masyarakat Suku Bantik yaitu Malalayang (Minanga), Singkil (Sikilri), Bailang (Bailran), Molas (Molrasa), Meras (Mahasa) dan Bengkol (Bengkolro).

Jeannette Eva Wentinusa, SE selaku Lurah Kelurahan Buha menerangkan bahwa wilayah Pemerintahan Kelurahan ini memiliki 8 Lingkungan dengan luas wilayah $1.328,80(\mathrm{~km} 2)$ dengan jumlah penduduk 9.489 jiwa. Kelurahan Buha sendiri masih mempunyai banyak kekayaan dan keberagaman kebudayaan yang masih terjaga sampai saat ini contohnya bahasa daerah yang masih di dunakan dalam keseharian masyarakat Bantik Buha, mahamba Bantik yaitu sejenis tarian maengket dan upasa yaitu tarian perang yang sejenis dengan tarian kabasaran,tari - tarian ini di tampilkan saat penjemputan tamu atau dalam rangka mengisi acara - acara tertentu. Selain potensi kebudayaan terdapat juga kekayaan kekayaan lainnya seperti pertanian dan peternakan yang dikelola oleh masyarakat setempat.

\section{Lokasi Kelompok}

Kelompok usaha bersama "Singkatuhang" berada di Kelurahan Buha Lingkungan 1, Kecamatan Mapanget, Kota Manado. Jarak Kelurahan Buha dari Pusat Kota Manado (zero point) kurang lebih $6 \mathrm{~km}$ yang dapat di jangkau dalam waktu 1/2 jam, batas wilayah dari sebelah Utara Kelurahan Buha sendiri berbatasan dengan Kelurahan Bengkol, sebelah Barat berbatasan dengan Kelurahan Bailang, sebelah Timur berbatasan dengan Kelurahan Kairagi Dua dan sebelah Selatan berbatasan dengan Kelurahan Sumompo. Dekatnya jarak dengan pusat Kota Manado memudahkan trasportasi dalam menjangkau kebutuhan keseharian masyarakat setempat.

\section{Proses Pembentukan Kelompok}

Pada tahun 2012 terbentuklah kelompok Usaha Bersama ternak babi ini di Kelurahan Buha dengan nama "Singkatuhang", sesuai dengan 
pengertiannya dalam bahasa daerah suku Bantik Buha yang artinya kekeluargaan. Pada awalnya kelompok ini hanyalah arisan kekeluargaanyang berlanjut menjadi sebuah usaha bersama untuk mengelola modal dari masing - masing anggota. Pengurus yang lama dipilih kembali secara aklamasi menjadi pengurus baru kelompok usaha bersama ternak babi "Singkatuhang" yang mempunyai 70 ekor ternak babi termasuk 6 ekor ternak betina (indukan) dan 1 ekor pejantan. Kelompok ini mengikuti aturan sistim informasi penyuluhan (simlus) yaitu harus memiliki struktur kepengurusan dan legalitas kelompok (punya sertifikat) yang diberikan oleh dinas terkait.

\section{Perkembangan Kelompok}

Kelompok Usaha Bersama "Singkatuhang" pada awalnya hanyalah peternak babi yang belum paham prilaku berternak yang baik, kelompok ini pada awalnya hanya beranggotakan 6 orang dan hanya memelihara 70 ternak babi termasuk 6 ekor ternak betina (indukan) dan 1 ekor pejantan.

\section{Pengelolaan kelompok tentang} perencanaan, pengorganisasian, pelaksanaan dan pengendalian adalah adalah serangkaian proses yang harus diterapkan kelompok usaha bersama ternak babi ini guna merespon permasalahan yang ada dilapangan dengan cara pengelolaan kelompok yang tepat.
Sesuai hasil penelitian dilapangan bahwa terjadi perubahan prilaku berternak babi yang positif dan peternak telah mampu mempraktekannya cara berternak babi dan pengelolaan kelompok yang baik dan benar, sehingga perkembangan kelompok mengenai perencanaan, pengorganisasian, pelaksanaan dan pengendalian/pengontrolan sesuai dengan harapan Dinas terkait untuk merubah prilaku kelompok "Singkatuhang" dalam perkembangan kelembagaan, pendampingan teknologi peternakan yang lebih baik. Pertambahan ternak yang terjadi juga merupakan suatu keberhasilan penyuluh yang sekarang mencapai 200 ekor ternak babi yang siap dipasarkan dan 14 ekor betina dan 6 ekor pejantan.

Melihat dari perkembangan kelompok mengenai perubahan prilaku yang positif dan analisis keuntungan, masing masing anggota mendapatkan Rp.20.634.500 dalam satu periode (limabulan)membuktikan bahwa penyuluh telah berperan dalam pembinaan kelompok usaha bersama "Singkatuhang".

\section{Peranan Penyuluh}

Dinas Pertanian, Kelautan dan Perikanan Kota Manado berkewajiban memberikan pembinaan kepada kelompok yang telah memiliki legalitas (punya sertifikat kelompok) yang terdaftar pada sistim informasi penyuluhan (simlus) secara online di Dinas tersebut. 
Penyuluh peternakan bertanggung jawab terhadap perkembangan kelembagaan (kelompok) dan memberikan pendampingan mengenai inovasi teknologi peternakan. Cara penyelesaian masalah oleh Dinas terkait dilakukan secara berjenjang. Sebelum melakukan penyuluhan penyuluh terlebih dulu turun kelapangan melakukan identifikasi masalah yang ada pada peternak untuk kembali ke Dinas guna menyususn cara penyelesaian masalah tersebut.

Aturan Dinas Pertanian, Kelautan dan Perikanan Kota Manado bahwa 1 Kelurahan hanya boleh dibina oleh 1 orang penyuluh yang minimal harus mempunyai 5 kelompok. Kelurahan Buha sendiri terdapat 5 kelompok aktif yaitu 4 kelompok Pertanian dan 1 kelompok ternak kambing, tetapi ada juga 4 kelompok tidak aktif yaitu 2 kelompok pertanian 1 kelompok peternak itik dan 1 kelompok ternak ayam pedaging. Agar pekerjaan sesuai dengan program dan visi misi maka penyuluh wajib melaporkan hasil kegiatan penyuluhan secara tertulis baik mingguan dan bulanan.

Dilapangan juga penyuluh wajib mengisi monitoring saat sedang melakukan penyuluhan yang telah disediakan dan dikontrol langsung minimal 1 kali dalam sebulan oleh Kepala Bidang Penyuluhan. Apabila Dinas Pertanian, Kelautan dan Perikanan Kota Manado mempunyai bantuan berupa bibit ternak, obat - obatan, alat dan mesin maka bantuan tersebut akan dibagikan sesuai dengan permintaan dan kebutuhan kelompok.

Menurut keterangan penyuluh lapangan bahwa ketika melakukan kegiatan penyuluhan tidak mengalami kendala dan mampu menyelesaikan masalah - masalah yang ada dalam kelompok tersebut sesuai tupoksi yaitu perkembangan kelembagaan dan pendampingan teknologi peternakan walaupun menangani 6 kelompok yang masih aktif dikelurahan Buha, pembagian waktu penyuluhan diatur oleh penyuluh menyesuaikan dengan kesempatan setiap kelompok yang sebelumnya telah dihubungi kemudian dilakukan penyusunan jadwal penyuluhan perkelompok, yang terpenting penyuluh harus memenuhi kegiatan penyuluhan 2 kali dalam 1 bulan perkelompok yang ada dikelurahan.

\section{Peranan Penyuluh Terhadap Pengetahuan}

\section{Peternak Babi}

Pengetahuan diperlukan untuk mengetahui perubahan pada peternak dengan adanya kegiatan penyuluhan.Pada awalnya peternak tidak mengetahui cara beternak yang tepat menurut hasil pengamatan peneliti dilapangan, pertanyaan mengenai pengetahuan peternak babi diberikan kepada masing - masing anggota menggunakan kuisioner untuk kemudian dilakukan tabulasi dan analisis data yang dikaitkan dengan teori yang ada. 
Tabel 1. Penilaian Peranan Penyuluh Terhadap Pengetahuan Peternak BabiSetelah Adanya Kegiatan Penyuluhan.

\begin{tabular}{|c|c|c|c|}
\hline NO & Parameter Pengetahuan Peternak & \multicolumn{2}{|c|}{ Penilaian (\%) } \\
\hline & & Ya/Tahu & Tidak/Tidak Tahu \\
\hline 1 & Cara pemberian pakan & 100 & \\
\hline 2 & Memilih jenis pakan berkualitas & 90 & 10 \\
\hline 3 & Jumlah pakan per hari & 100 & \\
\hline 4 & Mengawinkan ternak babi & 80 & 20 \\
\hline 5 & Memilih bibit berkualitas & 80 & 20 \\
\hline 6 & Waktu babi siap dikawinkan & 70 & 30 \\
\hline 7 & Memberikan vaksin pada ternak & 90 & 10 \\
\hline 8 & Mengobati ternak yang sakit & 90 & 10 \\
\hline 9 & Cara pengelolaan kelompok & 70 & 30 \\
\hline
\end{tabular}

Hasil penelitian pada Tabel 1 memadai terhadap terhadap suatu hal maka menunjukan bahwa dari kesembilan dapat memberikan pengaruh secara optimal parameter pertanyaan untuk Peranan pada peningkatan produktifitas untuk penyuluh dalam hal merubah perilaku keberhasilan usaha ternak.

pengetahuan peternak dinilai sudah tepat, Peranan Penyuluh Terhadap Ketrampilan yang sebelumnya tidak tahu menjadi tahu.

Pengetahuan kelompok usaha bersama Peternak Babi

ternak babi "Singkatuhang" dinilai sudah

Ketrampilan sangat diperlukan agar baik dari presentase 10 anggota yang terjadi perubahan yang lebih baik dari sebelumnya dalam segi pemeliharaan ternak diberikan pertanyaan minimal 7 anggota babi setelah adanya penyuluhan, hasil telah mengetahui cara beternak yang tepat dari penyuluh.

Pernyataan ini juga didukung oleh Dali (2017) bahwa pengetahuan adalah kesan dalam pikiran manusia sebagai proses panca indra, yang berbeda dengan kepercayaan, takyul dan penerangan yang keliru. Dengan pengamatan dilapangan yang dilakukan peneliti terhadap peternak bahwa dalam melakukan pemeliharaan mereka belum terampil sebelum adanya kegiatan penyuluhan.Tabel 2 menjelaskan parameter perubahan ketrampilan peternak setelah ada penyuluhan 
Tabe12. Penilaian Peranan Penyuluh Terhadap Ketrampilan Peternak Babi Setelah Adanya Kegiatan Penyuluhan.

\begin{tabular}{clrc}
\hline NO & Parameter Ketrampilan Pe te rnak & \multicolumn{2}{c}{ Penilaian (\%) } \\
\hline & & Terampil & Tidak Te rampil \\
\hline 1 & Cara pemberian pakan & 100 & 0 \\
2 & Memilih jenis pakan berkualitas & 90 & 10 \\
3 & Jumlah pakan per hari & 100 & 0 \\
4 & Mengawinkan ternak babi & 70 & 30 \\
5 & Memilih bibit berkualitas & 80 & 20 \\
6 & Waktu babi siap dikawinkan & 70 & 30 \\
7 & Memberikan vaksin pada ternak & 90 & 10 \\
8 & Mengobati ternak yang sakit & 90 & 10 \\
\hline
\end{tabular}

Hasil penelitian pada Tabel 2 memberikan pengaruh yang baik secara menunjukan bahwa peternak babi sudah baik optimal pada usaha berternak.

dalam hal ketrampilan memelihara ternak, Peranan Penyuluh Terhadap Sikap sehingga dapat disimpulkan bahwa usaha Peternak Babi dari penyuluh sudah tepat dalam merubah ketrampilan peternak, minimal 7 dari 10 anggota kelompok sudah terampil dalam berternak.

Ketrampilan adalah kecakapan yang berhubungan dengan tugas yang dimiliki dan dipergunakan oleh seseorang pada waktu yang tepat, menurut Hafsah (2009) dengan adanya pemahaman ketrampilan yang Sikap diperlukan oleh seorang peternak agar mampu memahami setiap ideide bahkan gagasan dari seorang penyuluh, terlihat dari hasil penelitian dilapangan sebelum adanya penyuluhan bahwa peternak masih menerapkan sistim pemeliharaan semi intensif yang belum menunjukan sikap yang baik dalam beternak, berikut tabel parameter memadai terhadap suatu hal maka dapat perubahan terhadap sikap peternak.

Tabel3. Penilaian Peranan Penyuluh Terhadap Sikap Peternak Babi SetelahAdanya Kegiatan Penyuluhan.

\begin{tabular}{clrc}
\hline NO & \multicolumn{1}{c}{ Parameter Sikap Peternak } & Baik & Tenilaian (\%) \\
\hline & \multicolumn{1}{c}{ Tidak Baik } \\
\hline 1 & Pandangan tentang penyuluhan & 90 & 10 \\
2 & $\begin{array}{l}\text { Mengikuti anjuran Pemberian pakan dan } \\
\text { pakan berkualitas }\end{array}$ & 90 & 10 \\
3 & $\begin{array}{l}\text { Mengikuti anjuran memilih bibit ternak } \\
\text { babi berkua litas }\end{array}$ & 80 & 20 \\
4 & Paham cara pemberian obat dan vaksin & 90 & 10 \\
5 & Paham waktu babi siap dikawinkan & 80 & 20 \\
6 & Pengelolaan kelompok & 70 & 30 \\
7 & $\begin{array}{l}\text { Mengerti informasi yang diberikan oleh } \\
\text { penyuluh }\end{array}$ & 90 & 10 \\
\hline
\end{tabular}


Hasil penelitian pada Tabel 3 menunjukan bahwa peranan penyuluh telah memberikan pengaruh positif dalam merubah sikap peternak babi "Singkatuhang", presentase dari 10 orang anggota minimal 7 anggota telah memiliki sikap yang baik dan tepat dalam berternak, sehingga dapat disimpulkan bahwa usaha dari penyuluh sudah tepat dalam merubah sikap peternak.

Pernyataan ini juga di dukung oleh Azwarat al.(2003) bahwa sikap adalah suatu pola prilaku, tendensi atau kesiapan antisipatif, predisposisi untuk menyesuaikan diri dalam situasi sosial. Secara sederhanasikap adalah respon yang telah terkondisikan, sehingga penerapan yang baik dan tepat memberikan pengaruh terhadap peningkatan usaha ternak.

\section{Analisis Pendapatan Usaha Kelompok} "Singkatuhang"

Pendapatan $=\mathrm{TR}-\mathrm{TC}$

TR atau total revenue adalah jumlah nilai penjualan ternak sedangkan biaya total atau total cost (TC) terdiri atas Fix Costdan Variable Cost. Keuntungan peternak dari usaha ternak babi diperoleh dengan mengurangkan biaya total dari penerimaan total

Biaya tetap, adalah biaya yang tidak berubah dengan peningkatan atau penurunanjumlah barang ataupun jasa yang dihasilkan sedangkan biaya variabel, adalah biaya yang berubah secara proporsional dengan aktifitas bisnis atau jumlah biaya marjinal terhadap semua unit yang diproduksi.

Tabel4. Analisis Pendapatan Usaha Kelompok "Singkatuhang"

\begin{tabular}{|c|c|c|}
\hline No & Jenis Biaya Tetap (Fix Cost) & Jumlah (Rp) \\
\hline 1 & Kandang & 16.250 .000 \\
\hline 2 & Alat dan Tempat Untuk Mencampur Makanan & 130.000 \\
\hline 3 & Listrik & 1.500 .000 \\
\hline \multirow[t]{2}{*}{4} & Lahan & 1.250 .000 \\
\hline & Total & 19.130 .000 \\
\hline No & Biaya Variabel (Variable Cost) & Jumlah (Rp) \\
\hline 1 & Pembelian Bibit & 160.000 .000 \\
\hline 2 & Makanan & 360.000 .000 \\
\hline 3 & Obat dan Vaksin & 485.000 \\
\hline \multirow[t]{2}{*}{4} & Tenaga Kerja & 12.300 .000 \\
\hline & Total & 532.785 .000 \\
\hline \multicolumn{2}{|l|}{ No } & Jumlah (Rp) \\
\hline 1 & Hasil Penjualan Ternak (Total Revenue) & Rp.720.000.000 \\
\hline 2 & Total Cost $=\mathrm{FC}+\mathrm{VC}$ & Rp.513.655.000 \\
\hline & $\begin{array}{l}\text { Keuntungan } \\
\end{array}$ & Rp.206.345.000 \\
\hline
\end{tabular}


Keuntungan kelompok usaha ternak babi "Singkatuhang" dalam satu periode pemeliharaan (lima bulan) sesuai pada tabel yang diatas adalah Rp.206.345.000, keuntungan tersebut akan dibagi sama rata kepada 10 orang anggota kelompok sesuai dengan yang tertuang pada ADRT yang ada. Masing - masing anggota memiliki keuntungan Rp.20.634.500.

\section{KESIMPULAN}

Peranan penyuluh telah merubah prilaku (pengetahuan, sikap dan ketrampilan) peternak babi dalam mengelola kelompok usaha bersama "Singkatuhang", disamping itu peranan penyuluh cukup mempengaruhi peningkatan pendapatan peternak yang lebih menguntungkan dibandingkan Upah Minimum Provinsi Sulut 2019.

\section{DAFTAR PUSTAKA}

Ali O,A.M., N.J. Kathuri and T.E.O.Wesonga. 2011. "Effective extensionmethods for increased food production in kakamega district"., Kenya: EgertonUniversity.Journal Of Agricultural Extension And Rural Development. 3(5):95-101.

Anwas,O.M. 2013. Pengaruh pendidikan formal pelatihan dan intensitas pertemuan terhadap kompetensi penyuluh pertanian.Jurnal Pendidikan dan Kebudayaan.19(1):50-62.

Azwar, Saifudin. 2013. Sikap Manusia : Teori Dan Pengukurannya. Yogyakarta . Pustaka Pelajar.
Bahua, M.I., A Jahi, P.S. Asngari, A Saleh, and I.G.P. Purnaba. 2013. Factors affecting theperformance agricultural extension and their impact at behavior maizefarmers in Gorontalo Province. Journal of Agricultural Education andExtension. 1:1-10.

Dali, I. 2017. Hubungan kinerja penyuluh pertanian lapangan dengan keberhasilan peternak sapi potong di Kecamatan Kwandang KabupatenGorontalo Utara. Jurnal Zootek 37(2):403-414.

Hafsah, M.J., 2009. Penyuluhan Peternakan Sapi di Era Otonomi Daerah. Jakarta:PT Pustaka Sinar Harapan.

Harinta, Y.W., 2011. Adopsi inovasi pertanian di kalangan petani di Kecamatan Gatak Kabupaten Sukoharjo. Jurnal Agrin. 15(2):164174.

Hidayat, S.I., 2009. Analisis kinerja penyuluh pertanian di wilayah kerja unit penyuluhan pertanian Sukodono, Sidoarjo. Jurnal:Habitat. 20(1):45-56.

Ivancevich, 2008. Perilaku Dan Manajemen Organisasi, Jilid 1 dan 2 Jakarta: Erlangga

Moleong., J. dan Lexy. 2007. Metodologi Penelitian Kualitatif, Penerbit PT Remaja Rosdakarya Offset, Bandung.

Nlerum, F.E., and P.D.Akanji. 2015.Analysis of agricultural extension teaching methods of bayelsa and rivers state agricultural development programmes. Canadian Open Applied Sociology Journal.1(1):1-6.

Priyono, M.I., D. Shiddieqy, Widiyantono dan Zulfanita. 2015. Hubungan kausal antara tingkat penguasaan teknologi, dukungan kelembagaan 
dan peran penyuluhan terhadap adopsi integrasi ternak. Jurnal Informatika Pertanian. 24(2):141148.

Rahardjo., Susilo dan Gudnanto. 2011. Pemahaman Individu Teknik Non Tes.Kudus: Nora Media Enterprise.

Sapar.,A. Jahi,P.S. Asngari, Amiruddin dan I.G.P. Purnaba. 2012. Kinerja penyuluh pertanian dan dampaknya pada kompetensi petani kakao di empat wilayah Sulawesi Selatan. .Jurnal Penyuluhan.8(1):29-41.

Soekanto, Soerjono (2002) Teori Peranan, Jakarta, Bumi Aksara. 